\title{
KEPEMIMPINAN KEMITRAAN TENTMAKER AKWILA DAN PRISKILA
}

\author{
Irawan Budi Lukmono \\ Dosen Sekolah Tinggi Teologi Gamaliel Surakarta \\ ibelodia@yahoo.com
}

\begin{abstract}
Secular professionals have their own strengths when involved in ministry in the church. They can make a great contribution to growth the church. This paper elevates the leadership of a tentmaker partnership between Aquila-Priskilla and Paul in the pioneering church at Corinth and Ephesus. Leadership partnership is done by applying the principles of: partnership networking, self-support, holistic approach, and discipleship.
\end{abstract}

Keywords: Leadership partnership, tentmaker, Corinth, Ephesians, church planting.

\begin{abstract}
ABSTRAKSI - Kaum profesional sekuler memiliki kekuatan tersendiri jika dilibatkan dalam pelayanan di gereja. Mereka bisa memberikan kontribusi yang besar dalam pertumbuhan jemaat. Tulisan ini mengangkat kepemimpinan kemitraan tentmaker antara Akwila-Priskilla dan Paulus dalam merintis jemaat di Korintus dan Efesus. Kepemimpinan kemitraan dilakukan dengan menerapkan prinsip-prinsip: jejaring kemitraan, finansial swadana, pendekatan holistik, dan pemuridan gereja rumah/ perusahaan.
\end{abstract}

Kata Kunci: Kepemimpinan kemitraan, pembuat tenda, Korintus, Efesus, perintisan jemaat.

\section{PENDAHULUAN}

Setiap kota di Perjanjian Baru memiliki ciri khas tersendiri. Di sisi lain, masing-masing kota di Perjanjian Baru juga memiliki permasalahan yang berbeda-beda. Termasuk juga dalam hal ini kota Korintus dan Efesus.

\section{A. Kota Korintus}

Korintus adalah kota modern yang terletak sekitar lima puluh mil sebelah barat kota Athena. Kota ini dikelilingi dataran Korintus yang subur. Di kota ini juga terdapat pegunungan Akrokorintus yang digunakan sebagai menara pengintai dan mengawasi dari bahaya musuh. Karena itu arti Korintus adalah "penjaga atau pengawas." Korintus adalah kota kosmopolitan terbesar di Yunani. Kota ini menjadi kota pelabuhan dan jalur perdagangan yang ramai. ${ }^{2}$ Sebagai ibu kota Akhaya, Korintus menjadi tempat tinggal gubernur Romawi. ${ }^{3}$

Selain itu, kota Korintus juga menjadi pusat industri tekstil. ${ }^{4}$ Korintus dibangun menjadi kota besar di bawah pemerintahan Romawi. Korintus meliputi seluruh Yunani

\footnotetext{
${ }^{1}$ Charles Ludwig, Kota-kota pada Zaman Perjanjian Baru, (Bandung: Kalam Hidup, 1983), hal. 41-46.

${ }^{2}$ Doris Irwin dan Catherine Scheel, Kisah Para Rasul, (Bandung: Kalam Hidup, 1990), 63-64.

${ }^{3}$ Donald Guthrie, Pengantar Perjanjian Baru Vol. 2, (Surabaya: Momentum, 2009), 27-28.

${ }^{4}$ Charles Ludwig, 41-46.
} 
selatan dan semenanjung Peloponnesus. Penduduk di Korintus merupakan orang-orang Romawi, Yunani dan sebagian dari orang Yahudi. ${ }^{5}$

Meski Korintus adalah kota yang megah, tetapi kota ini memiliki hal-hal negatif yang dilakukan oleh penduduknya. Kota ini identik dengan perilaku amoral. ${ }^{6}$ R. Dixon menulis, Korintus adalah kota percabulan seksual. ${ }^{7}$ Bahkan Donald Guthrie menyebut Korintus adalah kota yang penuh kebejatan dan kerusakan moral. ${ }^{8}$ Selain itu, terdapat juga kuil Aphrodite sebagai tempat penyembahan berhala. $^{9}$

Tidak hanya itu, di kota ini juga terdapat seribu imam wanita yang menjadi pelacur bakti. Kehidupan yang sarat dengan kenajisan dan pestapora. ${ }^{10}$ Kota yang memberi kesempatan dosa merajalela (keangkuhan, percabulan, dan hawa nafsu). ${ }^{11}$ Korintus kota kaya secara materi, namun angkuh secara intelektual dan bejat secara moral. $^{12}$

\section{B. Kota Efesus}

Efesus adalah kota yang kaya, masyur, dan ramai. Seperti Korintus, Efesus merupakan kota pelabuhan dan perdagangan. Tetapi di balik kebesaran kota Efesus, terdapat kuil Artemis atau kuil Diana. Dengan adanya kuil ini, menunjukkan bahwa penduduk Efesus adalah penyembah berhala. Selain itu dosa perilaku amoral dan kepercayaan pada takhayul mewarnai kehidupan penduduk Efesus. ${ }^{13}$

Dari dua kota di atas (Korintus dan Efesus), dapat diketahui kondisi dan permasalahannya. Kedua kota itu merupakan kota besar yang memiliki prospek yang bagus untuk dunia

\footnotetext{
${ }^{5}$ www.wikipedia.com

${ }^{6}$ Charles Ludwig, 41-46.

${ }^{7}$ R. Dixon, Tafsiran Kisah Para Rasul, (Malang: Gandum Mas, 1981), 128-133.

${ }^{8}$ Donald Guthrie, 27-28.

${ }^{9}$ Doris Irwin dan Catherine Schell, 63-64.

${ }^{10}$ www.gkybsd.org

${ }^{11} \mathrm{http}: / /$ pemudastemi.id

${ }^{12}$ Stanley. H. Morton et.al, Alkitab Penuntun

Hidup Berkelimpahan, (Malang: Gandum Mas, 2012), 1877.

${ }^{13}$ Charles Ludwig, 71-80.
}

kerja. Kota yang tepat untuk para pekerja (kaum profesional). Namun, sekaligus kedua kota itu juga sangat bejat kehidupan moralnya. Penduduknya membutuhkan pemimpin tentmaker yang mampu menjangkau, memuridkan, menjawab kebutuhan dan permasalahan hidup mereka.

Penduduk Korintus dan Efesus membutuhkan pemimpin yang dekat dengan dunia kerja, tetapi mumpuni mengajarkan kebenaran firman Tuhan. Dalam hal ini, Tuhan telah mengirim Paulus untuk merintis jemaat (gereja) di kota Korintus dan Efesus. Paulus tidak sendiri. Ia memiliki tim pelayanan yang solid. Akwila dan Priskila (Priska) adalah tim pelayanan Paulus. Sebuah tim yang membangun kemitraan dengan baik dan berdampak. Tanpa bermaksud mengabaikan Paulus, penulis akan menyoroti kepemimpinan kemitraan tentmaker Akwila dan Priskila.

\section{KEPEMIMPINAN KEMITRAAN TENTMAKER}

\section{A. Akwila dan Priskila}

Akwila dan Priskila adalah pasangan suami istri yang saleh. Nama Akwila berarti "sang rajawali" atau an eagle. Dalam bahasa Ibrani, "Nesher." Sedangkan dalam bahasa Latin, "Aquilla."14 Nama Priskila berarti "yang patut dimuliakan, rendah hati, dan antik." ${ }^{15}$ Akwila dan Priskila merupakan sepasang suami-istri pada abad pertama Masehi. ${ }^{16}$ Priskila masih keturunan bangsawan Romawi (keluarga Acilian). Sedangkan Akwila adalah tukang kemah sederhana dari Pontus, Asia Kecil. ${ }^{17}$ Pada awalnya, Akwila dan Priskila tinggal di Roma (Kis. 18:2). Namun Kaisar Claudius mengeluarkan dekrit atau perintah

\footnotetext{
${ }^{14} \mathrm{http}: / /$ gkinrevival.blogspot.co.id.

${ }^{15} \mathrm{http}: / /$ sanrella.blogspot.co.id/2012/09/artipriskila.htm.

${ }^{16}$ W.R.F. Browning, Kamus Alkitab: Panduan Dasar ke dalam, Kitab-kitab, Tema, Tempat, Tokoh, dan Istilah Alkitabiah, (Jakarta: BPK Gunung Mulia, 2007).

${ }^{17}$ William Barclay, Pemahaman Alkitab Setiap
} Hari Surat Roma, (Jakarta: BPK Gunung Mulia, 2007), 310-312. 
berbau anti-bangsa semit (Yahudi). Dekrit ini dikeluarkan pada tahun 52 masehi. ${ }^{18}$ Semua orang Yahudi harus keluar dari Roma. Bagi Kaisar Claudius, orang-orang Yahudi adalah sumber masalah dan kerusuhan. ${ }^{19}$ Pada waktu itu, orang Yahudi sangat dibenci dan layak diusir dari Roma. ${ }^{20}$ Akwila dan Priskila tak luput dari dampak dekrit Kaisar Claudius, sehingga mereka harus meninggalkan Roma, menuju Korintus.

\section{B. Kepemimpinan Kemitraan Tentmaker Akwila dan Priskila}

Korintus adalah kota pertama Paulus bertemu dengan Akwila dan Priskila. Mereka bekerja bersama-sama mengembangkan usaha sebagai pembuat tenda (tentmaker). Mereka bermitra dalam profesi dan pelayanan (Kis. 18:3). Di kota Korintus dan Efesus, mereka menjadi mitra atau tim pengusaha dan pelayan Injil yang hebat (Kis. 18:18-21). Inilah yang disebut a tentmaker missionary. Menurut Ruth Siemens, a tentmaker misisionary adalah:

"Seorang yang terlatih dan memiliki pengalaman sebagai pekerja Kristen, memiliki motivasi misi, dipimpin oleh Allah ke dalam pelayanan lintas budaya untuk membuat Yesus Kristus dikenal dan dengan biayanya sendiri melayani dalam konteks pekerjaan sekuler dan pendidikan." 21

Sularso Sopater menjelaskan, pengertian tentmaker adalah seseorang yang bekerja sendiri untuk memenuhi kebutuhan hidupnya sembari melayani pemberitaan Injil. ${ }^{22}$

Ada beberapa prinsip dalam kepemimpinan tentmaker. Berikut penjelasan prinsipprinsip tersebut:

1. Jejaring Kemitraan (Partnership Networking)

${ }^{18}$ William Barclay, 309.

${ }^{19}$ W.R.F. Browning, 310-312.

${ }^{20}$ William Barclay, Pemahaman Alkitab Setiap Hari Surat 1 \& 2 Korintus, (Jakarta: BPK Gunung Mulia, 2008), 297.

${ }^{21}$ Ruth Siemens, Secular Options form Missionary Work, Perspectives on The World Christian Movement a Reader, 772

${ }^{22}$ Sularso Sopater, Fenomena GKJ Sambirejo Sragen, (Bahtera, Nomor 1, 2002), 9.
Akwila dan Priskila adalah pengusaha tenda. Mereka menyambut kedatangan Paulus di Korintus dengan baik. Bahkan selama 1,5 tahun Paulus tinggal di rumah mereka dan bekerja bersama-sama dalam dunia profesi, pembuat tenda. Akwila, Priskila, dan Paulus adalah rekan bisnis yang solid. Selain, membangun jejaring kemitraan melalui bisnis bersama, Akwila dan Priskila belajar firman Tuhan dari Paulus. Bagi mereka, Paulus bukan hanya rekan bisnis, tetapi juga rekan dalam pelayanan. ${ }^{23}$

Dari kemitraan ini juga, Paulus berterima kasih pada Akwila dan Priskila karena pasangan suami-istri ini turut menguatkan gereja mulamula. Akwila dan Priskila membantu Paulus dalam pelayanan, termasuk menolong Timotius (anak didik Paulus) saat di Efesus (2 Tim. 4:19). ${ }^{24}$ Berdirinya jemaat di Korintus dan Efesus atas peran serta dan bantuan Akwila dan Priskila kepada Paulus. $^{25}$

Akwila dan Priskila adalah mitra pelayanan yang penuh pengabdian, sehingga pada saat rasul Paulus pergi ke Anthiokia, Akwila dan Priskila mendapat kepercayaan untuk mengawasi pelayanan. ${ }^{26}$ Bahkan, Akwila dan Priskila rela mempertaruhkan nyawa mereka demi pelayanan yang dikerjakan bersama Paulus (Rm. 16:3-4). Dave Hagelberg menyebut "mempertaruhkan nyawa" sama dengan mempertaruhkan leher atau tenggorokan mereka demi Injil Kristus. ${ }^{27}$

Membangun kemitraan berarti membuka diri dan bekerjasama dengan orang atau pihak lain. Mitra yang dihadirkan Tuhan untuk kita berfungsi agar saling menguatkan, mengasah, saluran berkat. ${ }^{28}$

${ }^{23}$ www.bible.org

${ }^{24}$ Warren Wiersbe, Setia di Dalam Kristus, (Bandung: Kalam Hidup, 1990), 202-203.

${ }^{25}$ J. Wesley Brill, Tafsiran Surat Korintus

Pertama, (Bandung: Kalam Hidup, 1991), 334.

${ }^{26}$ Warren Wiersbe, Hikmat di Dalam Kristus,

(Bandung: Kalam Hidup, 1990), 212-213.

${ }^{27}$ Dave Hagelberg, Tafsiran Roma, (Bandung:

Kalam Hidup, 1993), 304-305.

${ }^{28}$ Yoel Anung Sundarto, Career VS Calling, (Yogyakarta: ANDI, 2007), 89-90. 


\section{Finansial Swadana (Self Support)}

Akwila dan Priskila dalam melakukan pelayanan menggunakan biaya sendiri. Mereka tidak merepotkan jemaat. Mereka membiayai pelayanan dengan apa yang mereka miliki. Hal ini menunjukkan kemandirian dalam keuangan.

Profesi mereka sebagai pengusaha tenda mampu menghasilkan keuangan yang dapat digunakan untuk menopang pelayanan pemberitaan Injil. Self support memungkinkan mereka menolong yang lemah, memberi tambahan uang bagi gereja untuk pekerjaan misi Allah. ${ }^{29}$

\section{Pendekatan Holistik (Holistic Approach)}

Dalam pelayanan tentmaker tidak ada dikotomi atau pengkotak-kotakan antara karyasakral yaitu pelayanan penuh waktu di bidang spiritual dan karya sekuler yaitu panggilan kerja di luar kegiatan spiritual gerejawi. Segala sesuatu dilakukan untuk Tuhan Yesus dan dalam rangka menghadirkan Injil. Sehingga, tentmaker bekerja demi Injil dan untuk Yesus Kristus. ${ }^{30}$

Hal ini menunjukan pendekatan holistik, yaitu profesi yang menjawab kebutuhan jasmani (ekonomi, finansial dll) dan rohani (keselamatan, kesejahteraan batiniah, dll). Iman dan profesi menjadi jalan Tuhan untuk membawa pengaruh (melalui peran, aktivitas, dan pekerjaan kita). Pekerjaan adalah tempat bagi kita bekerja bagi Allah dan berkontribusi bagi kesejahteraan manusia. ${ }^{31}$

4. Pemuridan Gereja Rumah/ Perusahaan (Discipleship \& Home Ministry)

Akwila dan Priskila merupakan pasangan suami-istri yang saleh, ramah, penuh perhatian terhadap jemaat. Buktinya, mereka menyediakan rumahnya (baik di Korintus, Roma maupun di Efesus) untuk bersekutu dan beribadah. Sampai abad ketiga belum ada gedung gereja,

\footnotetext{
${ }^{29}$ Luther M. Door, The Bivocational Pastor, (Tennesse: Broadman Press, 1983), 14.

${ }^{30}$ Tri Budiharjo, Prospek Missionary/Tentmakers Indonesia dalam Penginjilan di Asia, Teologi Injili Suatu Alternatif?Dired. Oleh Hadi Winoto, (Malang: STT I-3, 1995), 113-116.

${ }^{31}$ Yoel A. Sundarto, 34-39.
}

karena itu Akwila dan Priskila menjadikan rumahnya menjadi gereja (1 Kor. 16:19).

Rumah Akwila dan Priskila menjadi pusat cahaya dan kasih Kristen yang menerima banyak orang. ${ }^{32}$ Rumah mereka menjadi tempat pemuridan dan pemulihan jemaat. Bahkan Akwila dan Priskila berkenan membawa Apolos ke rumah mereka untuk mengajarkan iman Kristen (Kis. 18:24-26). Zaman sekarang, kaum profesi juga dapat melakukan hal ini dengan menjadikan rumah atau perusahaannya sebagai home ministry.

Di tengah masyarakat yang hidup dalam dunia kerja dan kebobrokan moral, Korintus dan Efesus membutuhkan pemimpin yang mampu menjawab kebutuhan hidup (jasmani dan rohani). Akwila dan Priskila dipakai Tuhan untuk hal tersebut. Secara profesi (dunia kerja) mereka mumpuni dan lincah. Secara rohani, mereka mampu menjangkau dan memuridkan banyak orang. Terbukti, kerja sama mereka dengan Paulus melahirkan jemaat Korintus dan Efesus.

\section{KESIMPULAN DAN SARAN}

\section{Kesimpulan}

Kepemimpinan kemitraan tentmaker menjadi jawaban bagi masyarakat yang hidup dalam kesibukan dunia kerja dan godaan dosa yang semakin mengganas (kebejatan moral, nafsu duniawi, dan penyembahan berhala). Seorang tentmaker lebih luwes, lincah, dan mudah diterima di dunia profesi atau masyarakat. Profesi yang dimiliki tentmaker menjadi pintu masuk untuk menjangkau banyak jiwa.

Akwila dan Priskila adalah pemimpin sekaligus suami-istri Kristen yang baik, dan menjadi teladan serta memberkati orang banyak. Karakter Akwila dan Priskila bisa diteladani, yaitu pasangan dan hamba Tuhan yang penuh kasih kepada Allah maupun sesama, pekerja keras, penuh tanggungjawab, setia pada keluarga, profesi, maupun pelayanan. Akwila dan Priskila merupakan contoh kepemimpinan kemitraan tentmaker (tentmaker leadership).

${ }^{32}$ William Barclay, Pemahaman Alkitab Setiap Hari Surat 1 \& 2 Korintus, 297-299. 
Kepemimpinan ini dapat diterapkan pada masa kini.

Kepemimpinan kemitraan tentmaker dapat menerapkan prinsip-prinsip: jejaring kemitraan (partnership networking), finansial swadana (self support), pendekatan holistik (holistic approach), dan pemuridan gereja rumah/ perusahaan (discipleship).

\section{Saran}

Gereja perlu memikirkan, melatih dan memperlengkapi serta mengutus kaum profesi (tentmaker) untuk terjun melayani jiwa-jiwa melalui profesi yang mereka kerjakan. Jemaat yang berprofesi sebagai dokter, pengusaha, dosen, lawyer, guru, seniman, akuntan, politikus dan lain sebagainya harus diperlengkapi dan diberdayakan untuk pelebarluasan Kerajaan Allah.

Kristus harus 'dihadirkan' dalam pekerjaan, keluarga, masyarakat, politik, studi, hobi, pelayanan dan lain sebagainya. Ketika kepemimpinan kemitraan tentmaker diterapkan maka kita dapat hidup secara maksimal dan mencapai sasaran Allah (Kel. 3:23; 1 Kor. 15: 31: pekerjaannya, motivasinya, cara-caranya). Semua yang dikerjakan adalah dalam rangka menghadirkan Kerajaan Allah dengan tanggung jawab dalam segala bidang, dan dengan motivasi yang benar, yaitu mengasihi Allah.

Gereja harus memahami bagaimana hidup melakukan sasaran Allah yang lebih luas (Kol. 3:23, 1 Kor. 15:3; 4:34). Allah bekerja proaktif (Kej. 1, Yoh. 9). Manusia diciptakan sebagai pekerja dan rekan sekerja Allah bahkan Kristus mati bagi pekerja, bukan pekerjaannya. Karena itu, gereja harus bergerak untuk memunculkan pemimpin-pemimpin tentmaker di masa kini, agar dapat menjawab kebutuhan hakiki manusia, tantangan dan perubahan jaman yang semakin kompleks. Dengan standar yang tinggi, yaitu dengan penuh perhatian, setia, disiplin tinggi, tanggung jawab, dan gaya bersahabat, rendah hati, mudah bekerjasama, antusias, niscaya akan berhasil.

Sekali lagi, Gereja perlu memikirkan, melatih atau memperlengkapi, dan mengutus kaum profesi (tentmaker) untuk terjun melayani jiwa-jiwa melalui profesi yang mereka kerjakan.

\section{DAFTAR PUSTAKA}

\section{Buku-buku:}

Anung Sundarto, Yoel, Career VS Calling, (Yogyakarta: ANDI, 2007).

Barclay, William, Pemahaman Alkitab Setiap Hari Surat Roma, (Jakarta: BPK Gunung Mulia, 2007).

Pemahaman Alkitab Setiap Hari Surat 1 \& 2 Korintus, (Jakarta: BPK Gunung Mulia, 2008).

Brill, J. Wesley, Tafsiran Surat Korintus Pertama, (Bandung: Kalam Hidup, 1991).

Browning, W.R.F. Kamus Alkitab: Panduan Dasar ke dalam, Kitab-kitab, Tema, Tempat, Tokoh, dan Istilah Alkitabiah, (Jakarta: BPK Gunung Mulia, 2007).

Budiharjo, Tri, Prospek Missionary/Tentmakers Indonesia dalam Penginjilan di Asia, Teologi Injili Suatu Alternatif? Dired. Oleh Hadi Winoto, (Malang: STT I-3, 1995).

Dixon, R Tafsiran Kisah Para Rasul, (Malang: Gandum Mas, 1981).

Guthrie, Donald, Pengantar Perjanjian Baru Vol. 2, (Surabaya: Momentum, 2009).

Hagelberg, Dave, Tafsiran Roma, (Bandung: Kalam Hidup, 1993).

H. Morton, Stanley et. al, Alkitab Penuntun Hidup Berkelimpahan, (Malang: Gandum Mas, 2012).

Irwin, Doris dan Catherine Scheel, Kisah Para Rasul, (Bandung: Kalam Hidup, 1990).

Ludwig, Charles, Kota-kota pada Zaman Perjanjian Baru, (Bandung: Kalam Hidup, 1983).

M. Door, Luther, The Bivocational Pastor, (Tennesse: Broadman Press, 1983).

Siemens, Ruth, Secular Options form Missionary Work, Perspectives on The World Christian Movement a Reader. 
Wiersbe, Warren, Setia di Dalam Kristus, Website:

(Bandung: Kalam Hidup, 1990).

, Hikmat di Dalam Kristus, (Bandung: Kalam Hidup, 1990).

http://gkinrevival.blogspot.co.id

http://pemudastemi.id

http://sanrella.blogspot.co.id/2012/09/artipriskila.html

Jurnal:

www.bible.org

Sopater, Sularso, Fenomena GKJ Sambirejo Sragen, (Bahtera, Nomor 1, 2002).

www.gkybsd.org

www.wikipedia.com 